\title{
Numerical Investigations on Seismic Bearing Capacity of Interfering Strip Footings
}

\author{
R. Boufarh, D. Saadi, M.S. Laouar
}

\begin{abstract}
The interaction between footings placed at close proximity affects the ultimate bearing capacity, settlement, and tilt of adjacent footings, especially under seismic loading. This paper reports the numerical finite element analysis to investigate the interference effect on the seismic bearing capacity of closely spaced rigid strip footings for a wide range of footing spacings, friction angles and horizontal acceleration factor. The results are presented in terms of seismic efficiency factors, and their variation was computed with respect to the change in the spacing ratio between the two footings. The results revealed that the increase in the earthquake acceleration leads to a reduction in efficiency gains owing to the failure zone of footings interfere altering the performance of the footings.
\end{abstract}

Keywords: bearing capacity, numerical analysis, seismic interference factors, strip footings.

\section{Introduction}

In the earliest phases of the development of Geotechnical Engineering, several researchers have exhaustively studied the bearing capacity and settlement of isolated shallow foundations in static condition (e.g., Bolton \& Lau (1993); Casagrande (1966); Hansen (1970); Meyerhof (1963); Prandtl (1920); Schmertmann et al. (1978); Terzaghi (1943); Vesic (1973)) and the history behind it is long. Whereas, not taking into consideration the seismic forces may be one of the major reasons for soil liquefaction, slope failure and infrastructure collapse. After earthquake motions such as Michoacán (Mexico City, 1985), Kobe (Japan, 1995), and the Bhuj (India, 2001), failure and excessive settlements of foundations of buildings have been noticed. Thus, the design of geotechnical structures in seismic areas needs particular consideration compared to the static case.

In the presence of true seismic forces, a rigorous theoretical method for estimating the bearing capacity of the foundations is difficult to perform. In the literature, several researchers have followed a simple approach by incorporating pseudo-static seismic forces to study the reduction in the bearing capacity of an isolated strip footing. In this field, the available theoretical researches are mostly based on (1) the limit-equilibrium method (Budhu \& Al-Karni (1993); Choudhury \& Rao (2005); Jahani et al. (2019); Kumar \& Kumar (2003); Pain et al. (2016); Richards et al. (1993); Saha \& Ghosh (2015); Sarma \& Chen (1995); Sarma \& Iossifelis (1990)); (2) the upper-bound theorem of limit analysis (Dormieux \& Pecker (1995); Ghosh (2008); Paolucci \& Pecker (1997); Soubra (1999)); (3) the lower- bound theorem of limit analysis (Chakraborty \& Mahesh (2016); Kumar \& Chakraborty (2013)); and (4) the method of stress characteristics (Cascone \& Casablanca (2016); Keshavarz \& Nemati (2017); Kumar \& Mohan Rao (2002), (2003)). In addition, there exist limited experimental and numerical studies related to the estimation of the seismic bearing capacity of an isolated strip footing (Huang (2019); Knappett et al. (2006); Luo et al. (2019); Pane et al. (2016); Shafiee \& Jahanandish (2010); Zeng \& Steedma (1998)).

However, in practice, the foundations encountered are rarely isolated, and they are placed in close proximity to each other, such as railway sleepers and foundations near the property lines, the interference of the stress zones beneath the footings affects the bearing capacity and settlement of the soil and hence, in certain instances can lead to major damage to the buildings from both the strength and serviceability points of view, especially in seismic conditions. Stuart (1962) was the first author to study the bearing capacity and the corresponding failure mechanism of two interfering footings. Later, based on his study, many researchers have investigated the interference effect on the ultimate bearing capacity of two closely spaced strip footings (Das \& Larbi-Cherif (1983); Ghosh \& Sharma (2010); Kumar \& Bhattacharya (2010); Kumar \& Bhoi (2008); Kumar \& Ghosh (2007); Kumar \& Kouzer (2008); Lee \& Eun (2009)).

Soil is defined as a complex multi-phase material, its stress, strain and strength being represented by pressure dependency with coupling between shear and volumetric behavior. With these complications, and to facilitate the solution of difficult Geotechnical problems, finite element

Rafik Boufarh, D.Sc., Associate Professor, Department of Civil Engineering, Faculty of Sciences and Technology, Larbi Tebessi University, Tebessa, Algeria. e-mail: rafik.boufarh@univ-tebessa.dz or rafikboufarh@gmail.com.

Djamel Saadi, D.Sc., Assistent Professor, Department of Civil Engineering, Faculty of Sciences and Technology, Larbi Tebessi University, Tebessa, Algeria. email: djamel.saadigtp@yahoo.fr.

Mohamed Salah Laouar, D.Sc., Full Professor, Department of Civil Engineering, Faculty of Sciences and Technology, Larbi Tebessi University, Tebessa, Algeria. email: c_laouar@yahoo.fr.

Submitted on March 23, 2020; Final Acceptance on April 30, 2020; Discussion open until September 30, 2020

DOI: $10.28927 /$ SR.432247 
methods have recently been widely used in many Geotechnical issues using sophisticated and advanced software, as well as powerful computers.

In recent years, several researchers employed numerical methods to determine the interference effect on the bearing capacity of neighboring footings in static conditions. Mabrouki et al. (2010) used the finite difference code FLAC to calculate the bearing capacity of two nearby strip footings, subjected to centered vertical loads with smooth and rough interfaces. The interference between the footings was investigated for several soil types, to determine the effects of cohesion, surcharge, and soil weight. The obtained results of efficiency factors were in good agreement with the solutions presented by Hazell (2004) . Using model tests and characteristics method, Hazell (2004) studied the interference between two surface rough and smooth strip footings on dense and loose sand; the solutions of the characteristics method showed similar trends to the experimental model on dense sand. Ekbote \& Nainegali (2019) studied the bearing capacity of two interfering strip footings embedded in cohesionless soil. The finite element software ABAQUS was used to evaluate the interference effect on the ultimate bearing capacity and the settlement of the foundations on homogeneous reinforced and unreinforced soil. The efficiency factors were presented for all terms of the bearing capacity equation. It was noted that for embedded interfering footings on reinforced soil medium, the reinforcement configurations have a significant impact effect on bearing capacity ratio. Acharyya \& Dey (2017) carried out an investigation of the bearing capacity of square footings resting on sloping ground and the effects of the governing parameters (angle of internal friction of soil, setback distance, steepness of the slope, footing width and depth of embedment of the footing). It was noticed that a setback distance equal to three times the footing width is sufficient for the foundation to act as a footing resting on horizontal ground. Shokoohi et al. (2019) applied the finite element and the limiting equilibrium methods to investigate the bearing capacity of two neighboring shallow strip foundations on sand. The results of bearing capacity ratio indicated that both methods are in good agreement with available data in the literature. Using PLAXIS 3D, Acharyya et al. (2020) carried out a series of finite element analyses to investigate the bearing capacity of a square footing placed on the crest of a slope. An optimal 7-10-1 artificial neural network (ANN) architecture was also developed for direct prediction of bearing capacity. It was observed that the shear strength parameters of the soil, the footing width, the embedment depth, and the slope inclination have a significant influence on the bearing capacity value.

In light of the above-mentioned works, the determination of the ultimate bearing capacity of neighboring strip footings under seismic condition hardly received any attention. Therefore, this investigation examines the effect of different (geotechnical, geometrical) parameters on the seismic ultimate bearing capacity of interfering strip footings, with the aid of 3-D finite element (FE) simulations using PLAXIS 3D V 2013. Moreover, the numerical model provides a description of the failure mechanism involved in the process of loading and failure of the footing.

\section{Background and Problem Definition}

For a shallow strip foundation, subjected to a centered vertical load, the static bearing capacity or ultimate load that a footing can sustain is usually calculated by superposition, where the contributions from soil cohesion c, soil unit weight $\gamma$ and surcharge loading $q$ are added together. Each contribution can be expressed as a bearing-capacity factor $N_{i}$ to give the total capacity (Terzaghi (1943)):

$$
q_{u}=0.5 \gamma B N_{\gamma}+q N_{q}+c N_{c}
$$

where, the bearing capacity factors depend on the frictional parameter $\varphi$ of the soil.

For studying the seismic bearing capacity of foundations in seismic areas, there are several approaches in theoretical studies: pseudo-static, pseudo-dynamic and full dynamic analysis. For the pseudo-static approach, the horizontal and vertical accelerations are applied to the structure at the center of gravity or the base level, and the problem is reduced to a static case of bearing capacity with inclined eccentric loads. In most of these solutions, the inertia of the soil mass is not included. In the pseudo dynamic approach, the failure surface developed during dynamic condition is assumed to be similar to the one under static loading and the equation of motion is derived from the dynamic equilibrium conditions. In this context, the effect of the earthquake on the supporting soil is included in the equilibrium equations. Also, the distribution of earthquake acceleration is included. The full dynamic approach is based on timehistory analysis using numerical methods.

In this study, the pseudo-static approach is adopted. The vertical downward static load applied by the structure to the footing is

$$
W=m g
$$

where $W=$ weight (vertical load), $m=$ Total mass applied by the structure, $g=$ acceleration due to gravity $\left(9.81 \mathrm{~m} / \mathrm{s}^{2}\right)$.

Moreover, another vertical load at the base of the footing results from the presence of vertical seismic acceleration. Therefore, depending on the direction of the vertical seismic acceleration, it can be stated clearly that the structure will apply a total vertical downward load of magnitude:

$$
W=\left(1 \pm k_{v}\right) m g
$$

where $k_{v}=$ vertical seismic coefficient.

Due to the horizontal seismic acceleration, the structure will apply a total horizontal load of magnitude

$$
H=k_{h} m g
$$


where $H=$ horizontal load and $k_{h}=$ horizontal seismic coefficient.

In a similar way, it can be written that the magnitude of vertical downward and horizontal body forces per unit volume will be equal to $\left(1 \pm k_{v}\right) \gamma$ and $k_{h} \gamma$, respectively.

Only the horizontal seismic coefficient $\left(k_{h}\right)$ is accounted for in the present study and the seismic forces are considered as horizontal loads applied to the foundation, the surcharge and the underlying soil. The horizontal load is obtained by multiplying the horizontal seismic coefficient $\left(k_{h}\right)$ by foundation load $(P)$, surcharge $(q)$, and soil weight $(W)$.

For seismic bearing capacity and pseudo-static method, the seismic bearing capacity factors $N_{c E}, N_{q E}$, and $N_{\gamma E}$ substitute $N_{c}, N_{q}$, and $N_{\gamma}$ in Eq. 1. According to the available research, these factors are dependent on the soil friction angle and the seismic coefficient.

$$
q_{u}=0.5 \gamma B N_{\gamma E}+q N_{q E}+c N_{c E}
$$

In the case of two identical footings, Stuart (1962) took into account the interference effect on the ultimate bearing capacity of neighboring strip footings, with factors $\xi_{y}, \xi_{c}$, and $\xi_{q}$ being employed to modify Terzaghi's superposition Eq. 1. The limit load is expressed in terms of bearing capacity factors and efficiency factors as follows:

$$
q_{u}=0.5 \gamma B N_{\gamma} \xi_{\gamma}+q N_{q} \xi_{q}+c N_{c} \xi_{c}
$$

The problem studied considers a footing of width $B$ in interference with another identical footing, at a distance measured from axis to axis as shown in Fig. 1.

The magnitude of the seismic ultimate bearing pressure $q_{u}$ is thus represented by the following expression:

$$
q_{u E}=0.5 \gamma B N_{\gamma E} \xi_{\gamma E}+q N_{q E} \xi_{q E}+c N_{c E} \xi_{c E}
$$

where $\xi_{(\gamma, q,)}$ are the seismic efficiency factors.

The three seismic efficiency factors in Eq. 7 can be calculated independently. They are defined as the ratio between the seismic bearing capacity of a single footing in presence of the other footings $q_{u E(i n t)}$ and the seismic bearing capacity of an isolated footing having similar dimension $q_{u E \text { (iso) }}$

$$
\xi_{(\gamma, c, q) E}=\frac{q_{u E(\text { int })}}{q_{u E(i s o)}}
$$

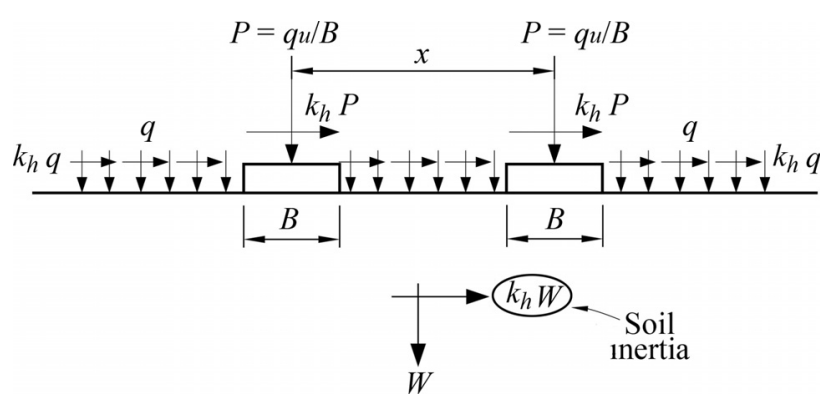

Figure 1 - Schematic diagram of the problem.
In order to estimate $\xi_{c E}$, a study was carried out in the case where the footings are acting on a weightless, cohesive-frictional soil with no surcharge; similarly, the factor $\xi_{q E}$ is calculated by considering a weightless and cohesionless soil. For the $\xi_{y E}$ factor, PLAXIS is able to carry out pseudo-static analysis by applying horizontal acceleration to the soil weight. In order to compute $\xi_{v E}$, the surcharge $(q)$ was kept equal to zero. A small value of $c$ was chosen to prevent numerical instabilities. The calculations were performed in two separate phases. In the first phase the pseudo-static analysis was performed and in the second phase, the external inclined stresses were applied to the foundation. Additionally, to calculate the combined efficiency factor $\xi_{\gamma c q}$ the soil is assumed to have non-zero values for the three parameters: cohesion $c$, friction angle $\varphi$ and density $\gamma$, and there is uniform surcharge pressure $q$.

\section{Numerical Modeling and Analysis}

In order to investigate the limit load for two closely spaced strip foundations in various conditions, nonlinear finite element analyses were performed to determine the seismic response as well as the settlement behavior of footings due to the application of horizontal loads. In the following, the problem definition and the finite element model are discussed. A numerical analysis using (Plaxis 3D-V 2013) software has been employed to separately characterize the load-settlement relationships of model strip footings. The computer program used in this study incorporates a fully automatic mesh-generation procedure, in which the geometry is divided into elements. Five different mesh densities are available in Plaxis, ranging from very coarse to very fine. In order to obtain the most suitable mesh for the present study, preliminary computations using the five available levels of global mesh coarseness were conducted. Since there is not too much difference in the results for different mesh configurations, it was decided to use the coarse mesh with refinement around the footing in all the analyses. The soil mechanical behavior is modeled using an elastic-perfectly plastic constitutive model following the Mohr-Coulomb failure criterion. The elastic parameters $E=2 \times 10^{4} \mathrm{kPa}$ and $v=0.3$ were assumed. The values of $c=10 \mathrm{kPa}, q=10 \mathrm{kPa}$, and $\gamma=16 \mathrm{kN} / \mathrm{m}^{3}$ were considered in order to compute the bearing capacity factors. The friction angle $\varphi$ is varied from $20^{\circ}$ to $40^{\circ}$ in $5^{\circ}$ increments, thus encompassing a wide range of soil types. It is assumed that the soil is completely dry and obeys the associated flow rule. The concrete footings were modeled using plate elements with linear elastic behavior. The normal stiffness and flexural rigidity of concrete foundations were considered as $5 \times 10^{6} \mathrm{kN} / \mathrm{m}$ and $9 \times 10^{3} \mathrm{kNm}^{2} / \mathrm{m}$, respectively. Several trial analyses were performed to choose an appropriate size for the soil domain. Finally, the generated mesh has dimensions of $6 B$ (width), $40 B$ (length) and $20 B$ (depth), while 
that of the footing was $2.0 \mathrm{~m}$ width, $x$ represents the axis to axis spacing between the footings.

The size of the finite element model is large enough to keep the boundary conditions at the bottom and the right and left sides from restricting the soil movement due to the footing load, so that the failure zones are freely developed without any interference from the boundary. The layout of mesh geometry is illustrated in Fig. 2.

"Standard fixity" has been applied on the numerical model, horizontal fixity was given to the vertical edges of the model. In the bottom edge of the model, both vertical and horizontal fixity were applied as the base of the model is assumed to be non-yielding.

The loading of rigid strip footing is modeled by imposing uniform inclined stresses at the surface nodes below the footing base. The inclination of imposed stresses is equal to the horizontal seismic coefficient $\left(k_{h}\right)$. The loading process is continued incrementally until $(a)$ soil relative stiffness reaches zero and $(b)$ the nodal out of balance forces get solved. The term "nodal out of balance forces" refers to the difference between the external loads and the forces that are in equilibrium with the current stresses. The stress vertical component that satisfies the above two conditions is the ultimate bearing capacity of the footing. After several attempts not reported for the sake of brevity, the best results, in terms of solution stability and convergence, were obtained. The finite element analyses are performed for $0 \leq k_{h} \leq 0.6$. The seismic efficiency factors were computed based on the superposition principle.

\section{Results and Discussion}

\subsection{Seismic bearing capacity factors for an isolated strip footing}

A preliminary simulation of the seismic bearing capacity of the system has been performed in order to check the validity and the degree of approximation of the numeri-

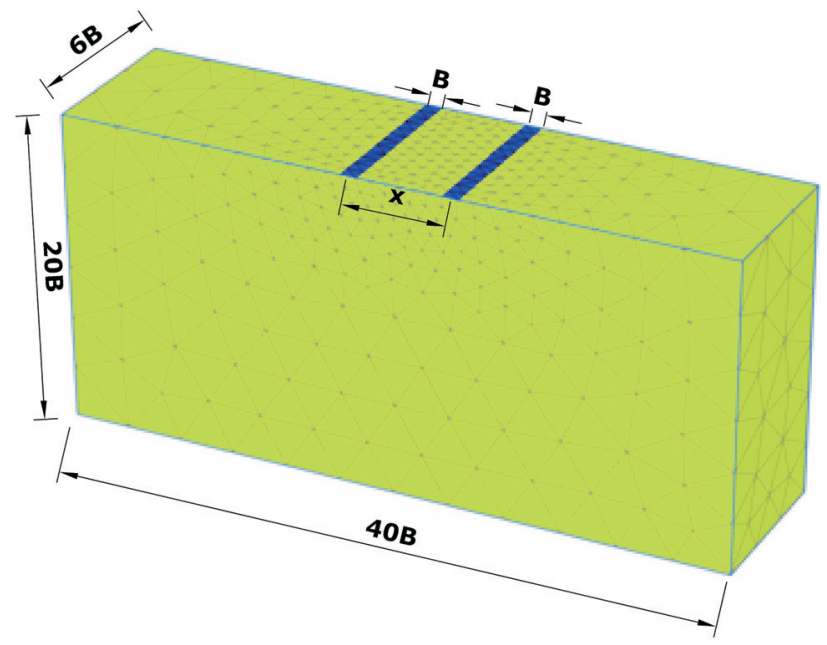

Figure 2 - Finite element mesh and geometry of the problem (Not to scale). cal procedure, by comparing the seismic bearing capacity factors obtained by the present numerical study with those obtained by other studies for $\varphi=30^{\circ}$, as shown in Figs. 3(a-c).

As seen in Figs. $3 \mathrm{a}$ and $3 \mathrm{~b}$, the values of $N_{c E}$ and $N_{q E}$ established from the present analyses are in good agreement with those reported by Kumar \& Mohan Rao (2002); Pane et al. (2016); Shafiee \& Jahanandish (2010); Soubra (1999) . Results are slightly higher than other solutions, which may be due to the difference in the method of analy-
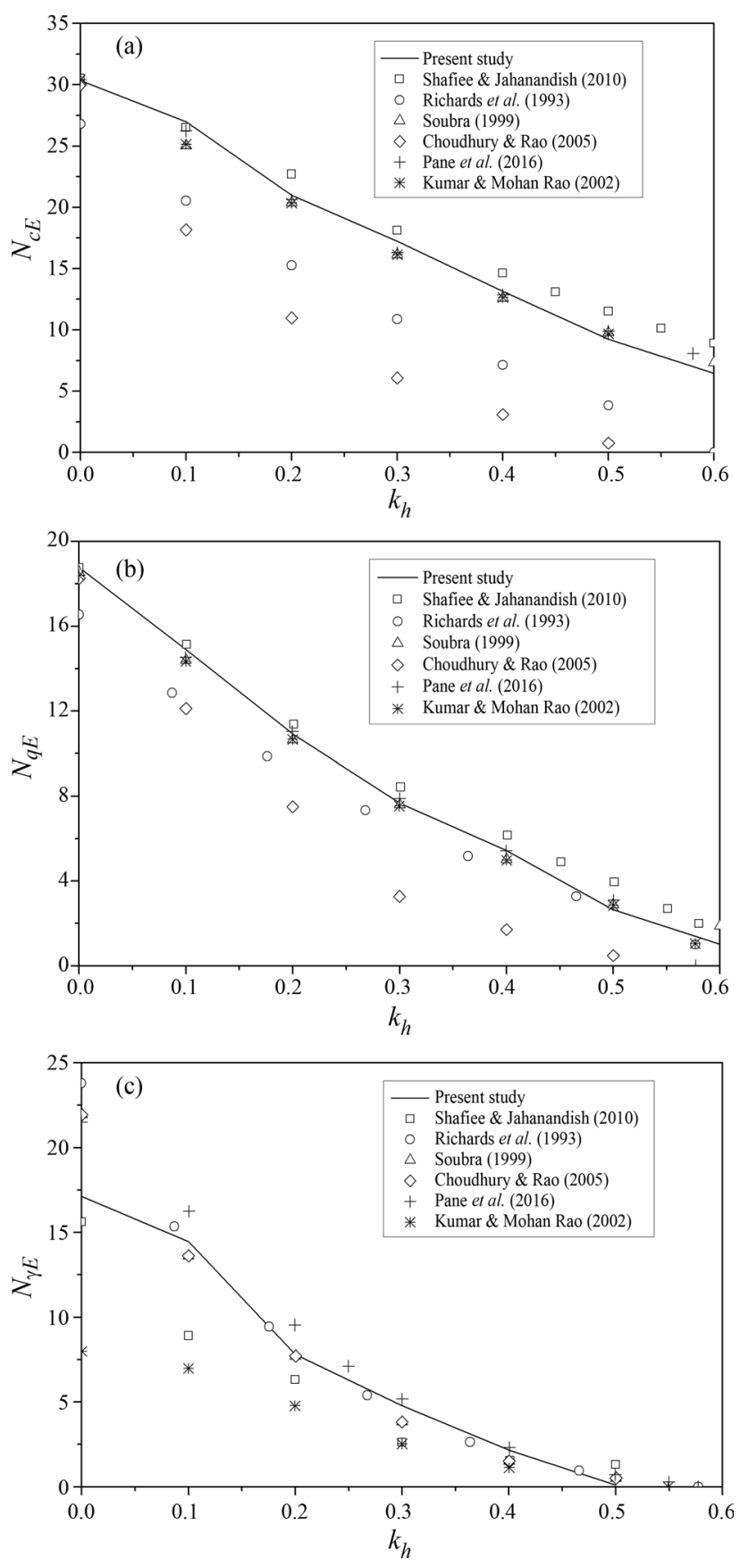

Figure 3 - Comparison of (a) $N_{c E}$, (b) $N_{q E}$ and (c) $N_{\gamma E}$ of the present study with some of the available solutions in the literature. 
sis. According to Fig. 3c, it is worth noting that, despite of the variation in the calculated bearing capacity factors, all of the solutions for $N_{\gamma E}$ are almost coincident. Based on this evidence, and on the consequent confidence in the adopted numerical procedure, the model was further used to simulate the interference effect of two strip footings under seismic loading conditions.

\subsection{Seismic efficiency factors}

In the case of dry cohesionless soils, Richards et al. (1993) found out that the phenomenon of shear fluidization (i.e., the material's plastic flow at a finite effective stress) may occur when $k_{h}$ is greater than $\tan (\varphi)$. In this case, soil acts like a viscous flow. Therefore, the maximum plausible value for $k_{h}$ is set to $\tan (\varphi)$ for calculations of $\xi_{q E \text {, }}$ and $\xi_{\gamma E}$ for friction angles $20^{\circ}$ to $30^{\circ}$. For $\varphi=35^{\circ}, 40^{\circ}$, the maximum value of $k_{h}$ is 0.6 . Taking into account the above-mentioned, a large number of numerical analyses were conducted for a wide range of seismic coefficient $k_{h}$ to estimate the values of seismic efficiency factors such as $\xi_{c E}, \xi_{q E}$, and $\xi_{\gamma E}$. The effect of horizontal seismic coefficient $k_{h}$ on the bearing capacity of strip footings for various spacing $(x / B)$ and friction angles $(\varphi)$ are presented in Figs. 4-6.

Figures 4 and 5 show the variation of efficiency factors $\xi_{c E}$ and $\xi_{q E}$, respectively. It can be observed that, for a spacing of $x=1 B$ there is no improvement in bearing capacity. If the distance between the footings is increased, for all values of horizontal seismic coefficient $k_{h}$ the efficiency factor increases until a peak for spacing between $1.5 \mathrm{~B}$ and $2.3 B$, followed by a progressive reduction to the value of 1 (value for widely spaced footings). Furthermore, for a given spacing between footings, the efficiency factor increases markedly with the increase in the friction angle.

The peak is found to be higher for smaller values of $k_{h}$ and spacing less than about $2.3 B$. For $\varphi=40^{\circ}$ with $k_{h}=0$, the maximum computed efficiency factor was approximately 1.5. Similarly, for $\varphi=40^{\circ}$ with $k_{h}=0.6$, the maximum values for $\xi_{c E}$ and $\xi_{q E}$ were found to be approximately 1.4 and 1.42 , respectively. It should be noted that the increase in $k_{h}$ leads to a reduction in efficiency gains as a result of the interaction between the foundations. For $k_{h}=0$ and spacing ratio greater than $3 B, 4 B, 5 B, 6 B$ and $7 B$, no interference effect was observed for friction angles $\varphi=20^{\circ}, 25^{\circ}, 30^{\circ}, 35^{\circ}$ and $40^{\circ}$ respectively. This distance reduced with increases in the $k_{h}$ value.

Figure 6 illustrates the variation of seismic efficiency factor $\xi_{\gamma E} v s$. spacing ratios $x / B$ and $k_{h}$ (for $20^{\circ} \leq \varphi \leq 40^{\circ}$ ). As seen, for all values of $k_{h}$ the values of $\xi_{\gamma E}$ are gradually reduced with an increase in $x / B$ for friction angles less than $25^{\circ}$. However, one can note a peak for the frictional angles $25^{\circ}, 30^{\circ}, 35^{\circ}$ and $40^{\circ}$. It can be also noted that, on an average, the peak of $\xi_{\gamma E}$ decreases by $10 \%$ for increasing of the horizontal seismic coefficient $k_{h}$.

\subsection{Combined efficiency factor $\left(\xi_{\gamma c q}\right)$}

Figure 7 illustrates the effect of variation of the horizontal seismic coefficient $k_{h}$ and angle of internal friction $(\varphi)$ on the combined efficiency factor $\xi_{\gamma c q}$. To calculate the combined efficiency factor $\xi_{\gamma c q}$ the soil is assumed to have cohesion $c$, friction angle $\varphi$ and density $\gamma$, and there is uniform surcharge pressure $q$.

It can be noticed that the results obtained for the combined efficiency factor $\xi_{\gamma c q}$ are lower than those obtained for $\xi_{\gamma}$ and they have the same overall pattern. It can be observed also that for any friction angle, the increase in $k_{h}$ resulted in the decrease of the gain in efficiency, the effect being more prominent at higher values of $\varphi$. Concerning the distance $x / B$ at which no interference effect occurs, as shown in Fig. 7, $x / B$ decreases by $1 B$ for increasing in horizontal seismic coefficient $k_{h}$ up to 0.6 . The reason can be attributed to the extension and the depth of the shear zone being less than when the footing was under the static loading condition.

\subsection{Failure mechanisms}

The extent of the plastic zones for $\varphi=40^{\circ}, c=10 \mathrm{kPa}$, $q=10 \mathrm{kPa}$ and $k_{h}=0$ at different $x / B$ ratios is shown in Fig. 8.

As seen, the shear zone is symmetrical about the center of the footings and similar to the failure mechanism proposed by Stuart (1962). Based in the geometry of the rupture surface in the soil mass assumed by Terzaghi (1943), Stuart (1962) suggested a failure mechanism for two closely spaced footings and some correction factors for the influence of the distance between the footings.

Figures $8(a, b)$ show the failure patterns when the distance between the two footings is very small or zero, the behavior is analogous to that of a single footing of width $2 B+x$. This behavior is referred to as the so-called "blocking effect". Based on this phenomenon, the soil between the footings behaves as a combined system and moves down as a single unit by loading application. If the spacing of the foundations is further increased, Figs. 8 (c, d) show the appearance of overlapping passive zones situated between the two footings. In this case the load capacity is influenced by the interference effect. From Fig. 8d, it can be seen that there is no overlap of failure surfaces at greater spacing. Also, the interference effect does not exist and the bearing capacity of each foundation is independent to the other.

Figures $9(\mathrm{a}-\mathrm{e})$ indicate the failure patterns for the same case $\left(\varphi=40^{\circ}, c=10 \mathrm{kPa}, q=10 \mathrm{kPa}\right)$ with $k_{h}=0.60$. It is clear that the failure pattern became non-symmetrical in the presence of earthquake acceleration; whereas the spreading of the plastic zone was more in the direction of horizontal pseudo-static body forces, and it increased with increases in the $k_{h}$ values. As seen from Figs. 9, the extension and the depth of the shear zone was less than for the footing under the static loading condition. For the spacing between footings above $5 B$, the shear zone is similar to the 

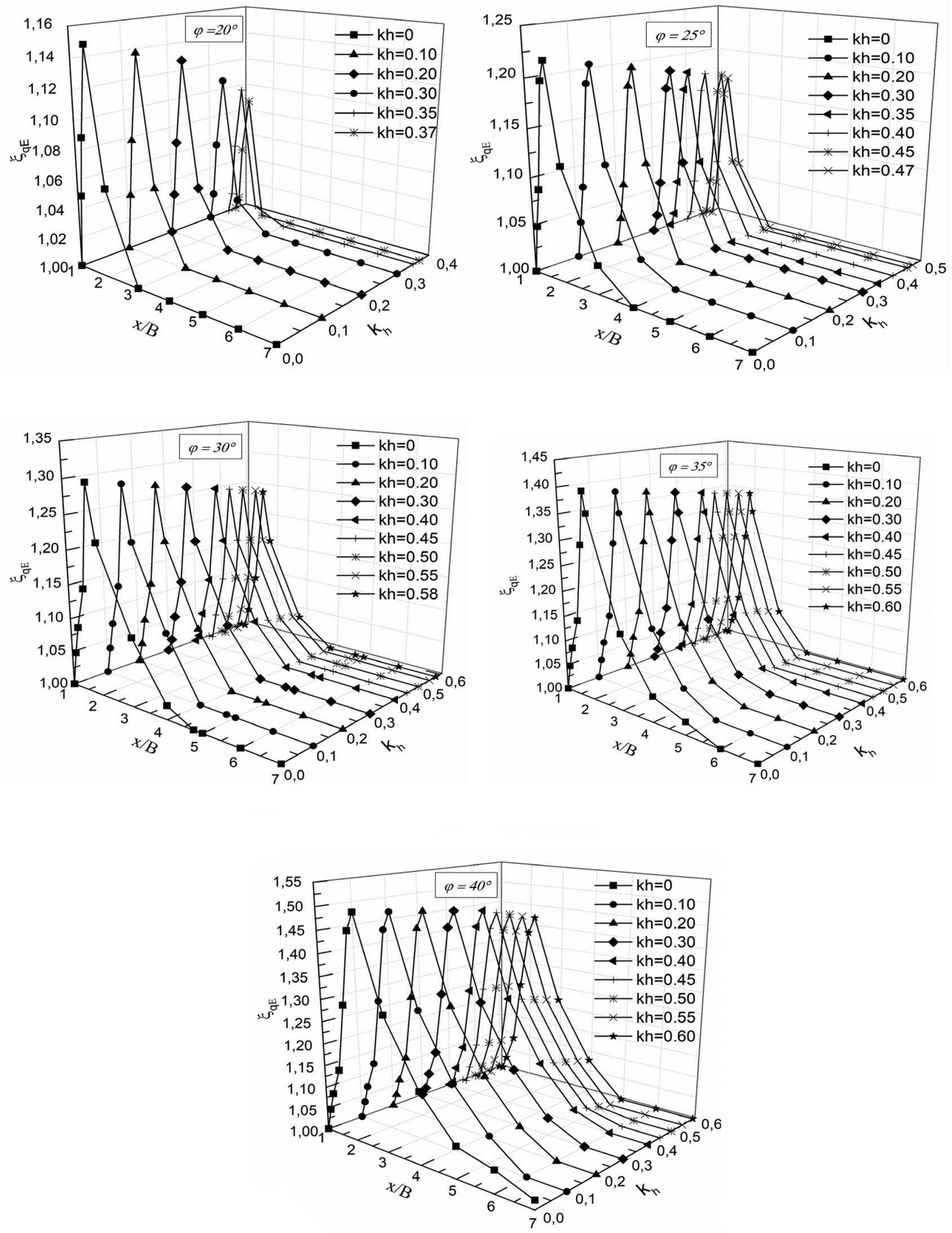

Figure 4 -Variation of efficiency factors $\xi_{q E}$ with $x / B$ and horizontal seismic coefficient $k_{h}$ for various values of angle of internal friction $\varphi$. 

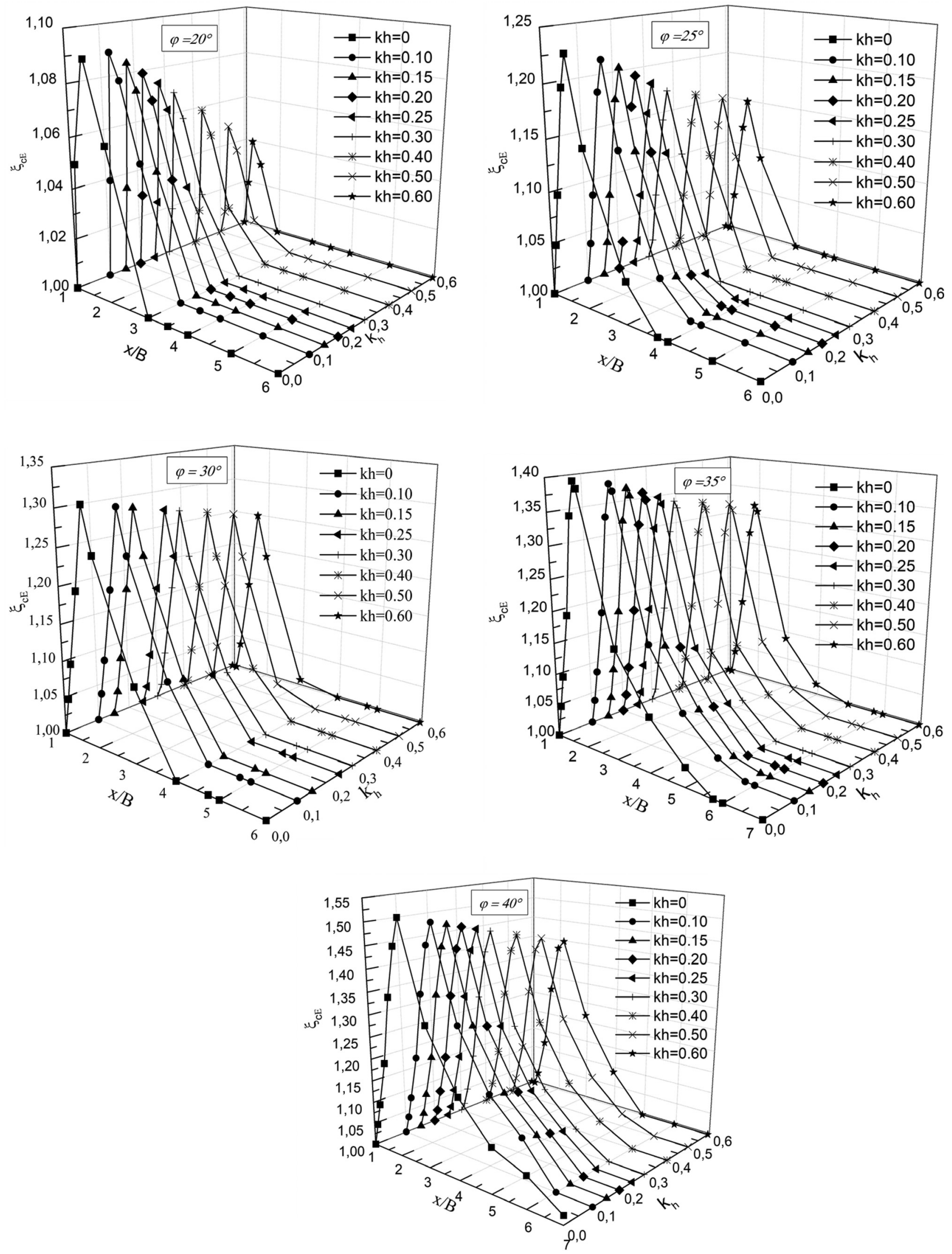

Figure 5 - Variation of efficiency factors $\xi_{c E}$ with $x / B$ and horizontal seismic coefficient $k_{h}$ for various values of angle of internal friction $\varphi$. 

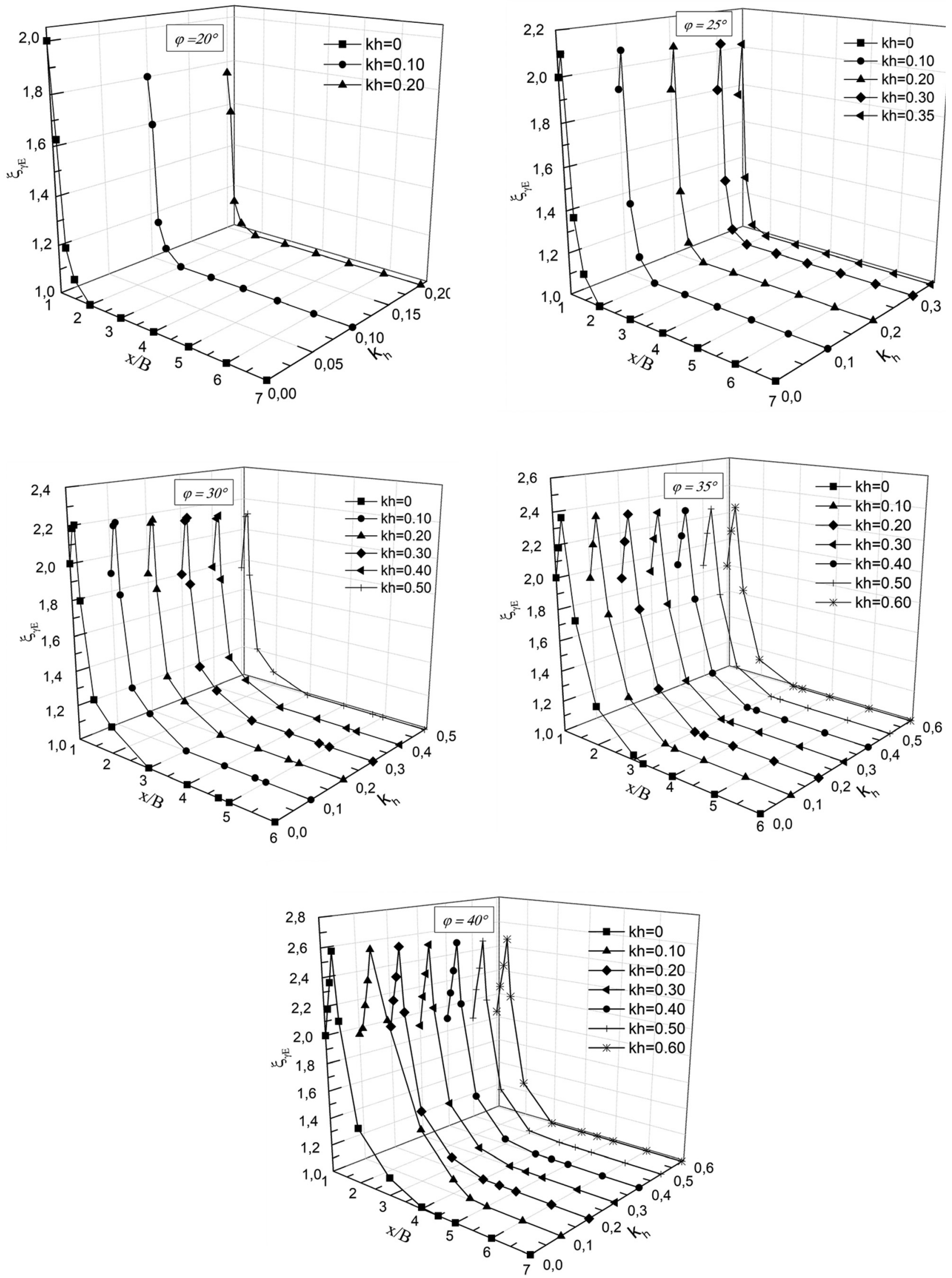

Figure 6 - Variation of efficiency factors $\xi_{\gamma E}$ with $x / B$ and horizontal seismic coefficient $k_{h}$ for various values of angle of internal friction $\varphi$. 

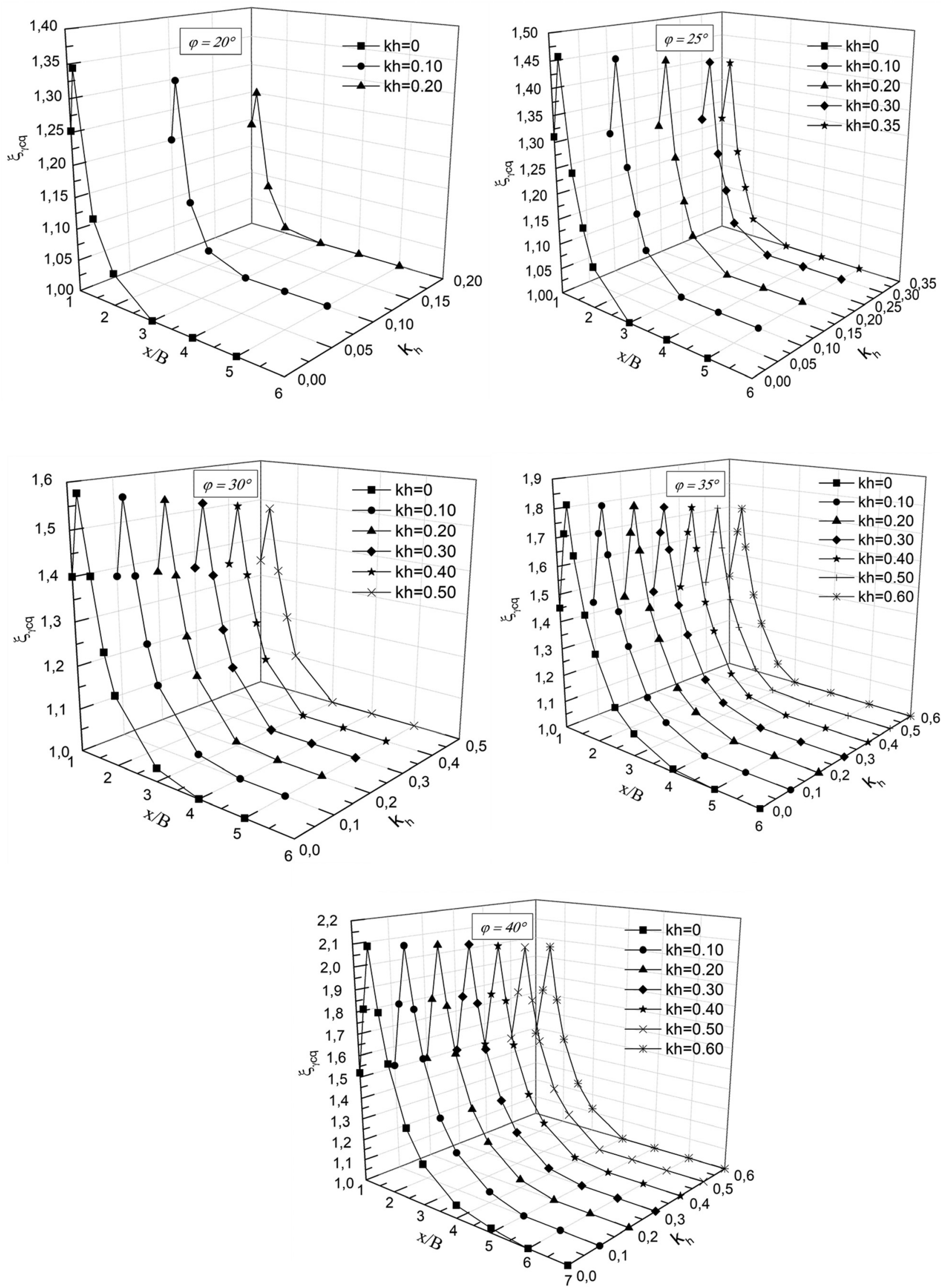

Figure 7 - Variation of efficiency factors $\xi_{\text {rcaE }}$ with $x / B$ and horizontal seismic coefficient $k_{h}$ for various values of angle of internal friction $\varphi$. 

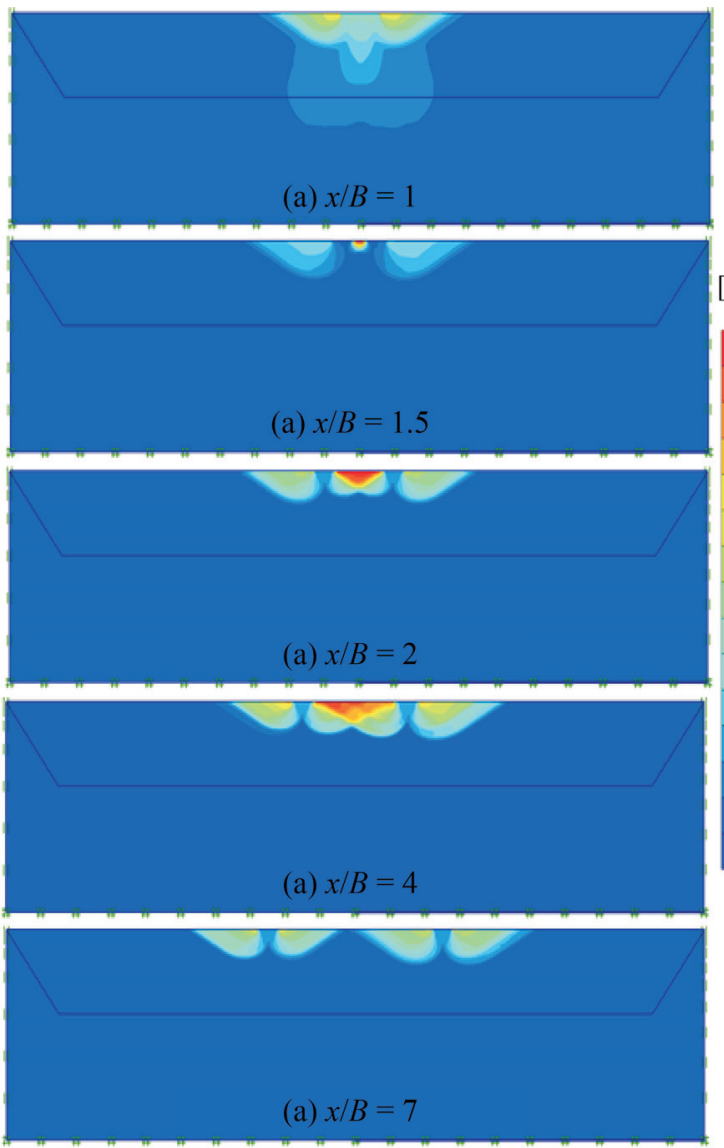

Figure 8 - Total incremental displacement for interfering strip footings under the static loading condition at various spacings $(x / B)$.

failure mechanism found by Kumar \& Mohan Rao (2002) and Cascone \& Casablanca (2016) in the analysis of an isolated strip footing. In addition, the settlement is smaller for larger spacings.

\subsection{Superposition error}

For the reason that the soil behaves nonlinearly specially under seismic action, the principle of superposition to compute the bearing capacity is not sufficiently accurate. For an isolated strip footing, Davis \& Booker (1971) found that the error is on the safe side by applying the previous assumption, While for two interfering footings, Mabrouki et al. (2010) concluded that the error is always on the safe side; it underestimates the bearing capacity. To illustrate the superposition effect on the bearing capacity of two interfering footings, direct calculations of bearing capacity were executed for $k_{h}=0$ and $k_{h}=0.3\left(\varphi=35^{\circ}\right)$. Using Terzaghi's assumption, the bearing capacity $q_{u}$ is calculated and compared in Fig. 10 with the results when $c, \gamma$, and $q$ are accounted for simultaneously.

As illustrated in Fig. 10, the range of error induced by applying the superposition principle is always on the safe side and the error percentage for seismic loading is greater than for the static case. Also, it is seen that the results for su-
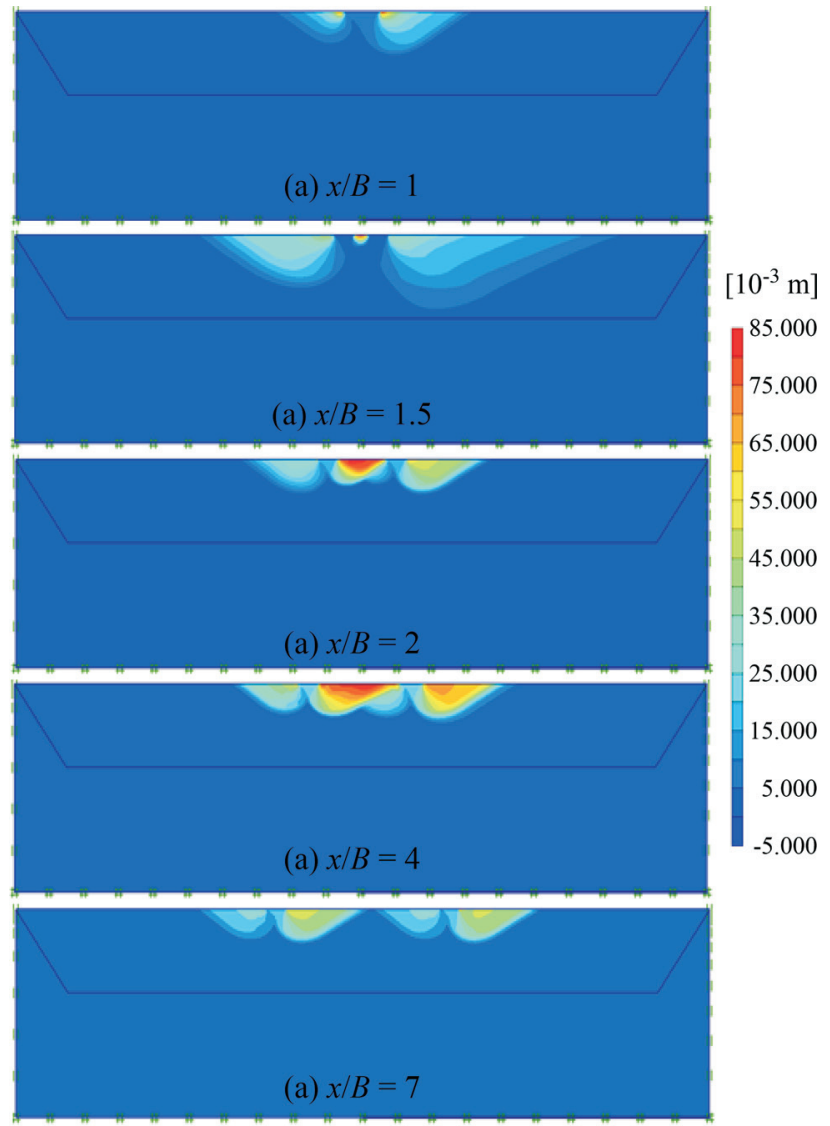

Figure 9 - Total incremental displacement for interfering strip footings under the seismic loading condition at various spacings $(x / B)$.

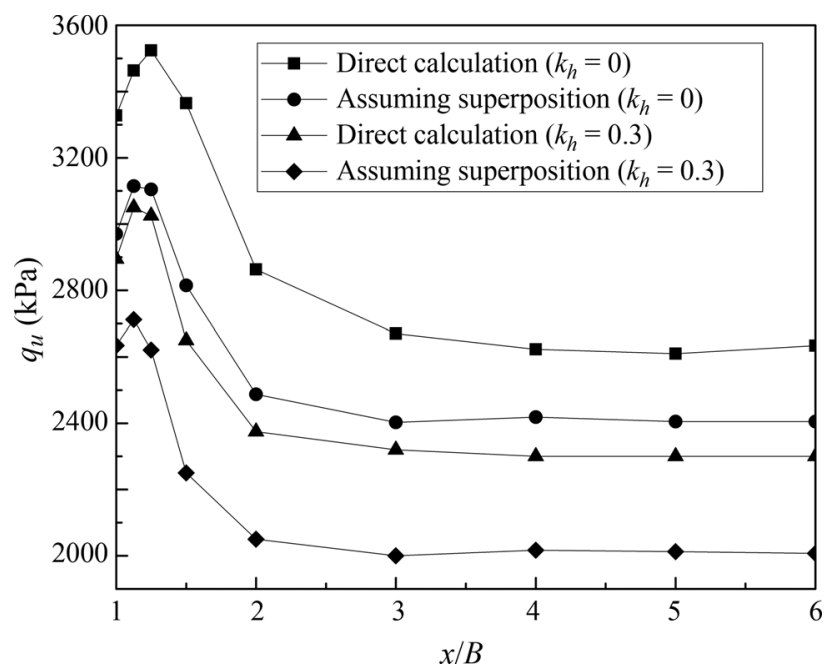

Figure 10 - Effect of superposition and the direct computations on static/seismic bearing capacity.

perposition principle in case of $k_{h}=0$ are very close to the direct calculation results in the case of $k_{h}=0.3$. In other words, using superposition assumption to estimate bearing capacity for interfering footing in the seismic case is more conservative than in the static case. 


\subsection{Effect of soil inertia}

For the case of an isolated strip footing, the effect of soil inertia on the seismic bearing capacity has been the subject of research by several authors such as Sarma \& Iossifelis (1990), Dormieux \& Pecker (1995), and Shafiee \& Jahanandish (2010). All these studies observed that the load inclination is the principal reason of reduction in bearing capacity, and hence the soil inertia forces can be neglected. In this paper, to study the effect of soil inertia on the seismic bearing capacity of two interfering footings, all computations were carried out in two general cases including/neglecting soil inertia. Figure 11 illustrates the variation of the seismic efficiency factor $\xi_{Y E}$ with $x=B$ in the case of horizontal seismic coefficient $k_{h}=0.3$ and for friction angles $\varphi=30^{\circ}$ and $40^{\circ}$. It was seen before that only the $\xi_{Y E}$ factor depends on the soil inertia.

In the case of two interfering footings, the soil inertia effects are found to be even less important than in the previous case of isolated strip foundations. This is shown in Fig. 11, where the results show a moderate reduction of the seismic efficiency factors $\xi_{y E}$ with $x / B$, that becomes less important when interference effects are taken into account. This effect is not large and can be accommodated within the static safety factor.

\section{Discussion}

This study does not examine the effects of vertical pseudo-static earthquake body forces on the magnitude of the foundation bearing capacity. Because the vertical body (gravitational) forces have already been incorporated in the problem, it is possible to integrate the impact of the vertical component of the earthquake acceleration simply by using the soil's revised unit weight $\left(\gamma_{r}\right)$. If $\pm k_{v} g$ is the magnitude of vertical seismic acceleration, then the value of $\gamma_{r}=\gamma(1 \pm$ $k_{v}$ ) should be used in place of $\gamma$ to account for the presence

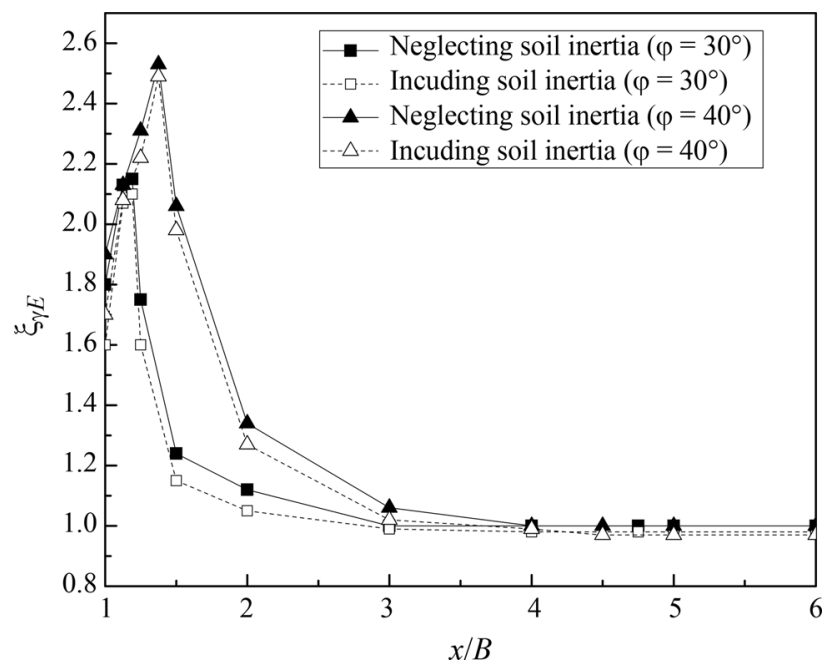

Figure 11 - Effect of soil inertia on the seismic efficiency factor $\xi_{Y E}$ for horizontal acceleration factor $k_{h}=0.3$ and for $\varphi=30^{\circ}$ and $40^{\circ}$. of $k_{v}$. Finally, the magnitude of the total bearing capacity in the presence of both the horizontal and vertical pseudostatic seismic forces can be calculated. It should be mentioned that for incorporating the effect of the vertical pseudo-static earthquake body forces on the bearing capacity factors for strip footings on a slope, Kumar \& Rao (2003a) also recommended a similar formulation.

\section{Conclusions}

In this study, various numerical analyses using PLAXIS 3D V 2013 were conducted to determine the interference effect on seismic bearing capacity of two footings for a wide range of spacings between the footings, friction angles and seismic coefficients. The pseudo-static approach has been adopted in the analyses. Based on the obtained results, the following important conclusions can be stated:

- The seismic bearing capacity factors obtained by the present numerical study are in good agreement with those obtained by other studies.

- For all values of the horizontal seismic coefficient, the seismic efficiency factors increase until a peak, followed by a gradual decrease to a constant value of one (value for widely spaced footings). The peak also decreases with increasing of $k_{h}$ intensity which is at a spacing distance less than about 2.3B. Moreover, the efficiency factor increases significantly with an increase in the friction angle. The above behaviours are the same in the case of static loads, but with relatively low values.

- Under seismic loading, the increase in the earthquake acceleration leads to a reduction in efficiency gains owing to the interaction between the foundations and the deformation of the shear zone.

- For all friction angles, it has been seen that the spacing required for interference to become extinct decreases with an increase in the earthquake acceleration value.

- The range of error induced by applying the superposition principle is always on the safe side and the error percentage for seismic loading is greater than for the static case.

- In the case of two interfering footings, the soil inertia effects are found to be even less important than in the previous case of isolated strip foundations. This effect is not large and can be accommodated within the static safety factor.

\section{References}

Acharyya, R. \& Dey, A. (2017). Finite element investigation of the bearing capacity of square footings resting on sloping ground. INAE Letters, 2(3):97-105. https://doi.org/10.1007/s41403-017-0028-6

Acharyya, R.; Dey, A. \& Kumar, B. (2020). Finite element and ANN-based prediction of bearing capacity of square footing resting on the crest of c- $\phi$ soil slope. International Journal of Geotechnical Engineering, 14(2):176187. https://doi.org/10.1080/19386362.2018.1435022 
Bolton, M.D. \& Lau, C. (1993). Vertical bearing capacity factors for circular and strip footings on Mohr-Coulomb soil. Canadian Geotechnical Journal, 30(6):1024-1033. https://doi.org/10.1139/t93-099

Budhu, M. \& Al-Karni, A. (1993). Seismic bearing capacity of soils. Geotechnique, 43(1):181-187. https://doi.org/10.1680/geot.1993.43.1.181

Casagrande, L. (1966). Subsoils and foundation design in Richmond. Journal of Soil Mechanics \& Foundations Div, 92(5):109-126.

Cascone, E. \& Casablanca, O. (2016). Static and seismic bearing capacity of shallow strip footings. Soil Dynamics and Earthquake Engineering, 84(1):204-223. https://doi.org/10.1016/j.soildyn.2016.02.010

Chakraborty, D. \& Mahesh, Y. (2016). Seismic bearing capacity factors for strip footings on an embankment by using lower-bound limit analysis. International Journal of Geomechanics, 16(3):1-11. https://doi.org/10.1061/(ASCE)GM.1943-5622.0000553

Choudhury, D. \& Rao, K.S.S. (2005). Seismic bearing capacity of shallow strip footings. Geotechnical \& Geological Engineering, 23(4):403-418. https://doi.org/10.1007/s10706-004-9519-9

Das, B.M. \& Larbi-Cherif, S. (1983). Bearing capacity of two closely-spaced shallow foundations on sand. Soils and Foundations, 23(1):1-7. https://doi.org/10.3208/sandf1972.23.1

Davis, E. \& Booker, J. (1971). The bearing capacity of strip footing from the standpoint of plasticity theory. Proc. 1st Conf. in geomechanics, New Zealand, Australian, pp. 276-282.

Dormieux, L. \& Pecker, A. (1995). Seismic bearing capacity of foundation on cohesionless soil. Journal of Geotechnical Engineering, 121(3):300-303. https://doi.org/10.1061/(ASCE)0733-9410(1995)121:3(300)

Ekbote, A.G. \& Nainegali, L. (2019). Interference of two closely spaced strip footings embedded in cohesionless fibre-reinforced foundation soil bed. Proc. 8th International Conference on Case Histories in Geotechnical Engineering, Philadelphia, Pennsylvania, pp. 454-464. https://doi.org/10.1061/9780784482094.041

Ghosh, P. (2008). Upper bound solutions of bearing capacity of strip footing by pseudo-dynamic approach. Acta Geotechnica,

$3(2): 115-123$. https://doi.org/10.1007/s11440-008-0058-z

Ghosh, P. \& Sharma, A. (2010). Interference effect of two nearby strip footings on layered soil: theory of elasticity approach. Acta Geotechnica, 5(3):189-198. https://doi.org/10.1007/s11440-010-0123-2

Hansen, J.B. (1970). A revised and extended formula for bearing capacity. Danish Geotechnical Institute Bull, 28(1):5-11.

Hazell, E. (2004). Interaction of Closely Spaced Strip Footings. Final year project report. Department of Engineering Science, University of Oxford.
Huang, C.-C. (2019). Experimental verification of seismic bearing capacity of near-slope footings using shaking table tests. Journal of Earthquake Engineering, 1-30. https://doi.org/10.1080/13632469.2019.1665148

Jahani, M.; Oulapour, M. \& Haghighi, A. (2019). Evaluation of the seismic bearing capacity of shallow foundations located on the two-layered clayey soils. Iranian Journal of Science and Technology, Transactions of Civil Engineering, 43(1):49-57. https://doi.org/10.1007/s40996-018-0122-3

Keshavarz, A. \& Nemati, M. (2017). Seismic bearing capacity of strip footings on fiber reinforced soils by the stress characteristics method. Journal of Engineering Geology, 10(3):3667-3688.

Knappett, J.; Haigh, S.K. \& Madabhushi, S.G. (2006). Mechanisms of failure for shallow foundations under earthquake loading. Soil Dynamics and Earthquake Engineering, 26(2-4):91-102. https://doi.org/10.1016/j.soildyn.2004.11.021

Kumar, J. \& Bhattacharya, P. (2010). Bearing capacity of interfering multiple strip footings by using lower bound finite elements limit analysis. Computers and Geotechnics, 37(5):731-736. https://doi.org/10.1016/j.compgeo.2010.05.002

Kumar, J. \& Bhoi, M.K. (2008). Interference of multiple strip footings on sand using small scale model tests. Geotechnical and Geological Engineering, 26(4):469477. https://doi.org/10.1007/s10706-008-9175-6

Kumar, J. \& Chakraborty, D. (2013). Seismic bearing capacity of foundations on cohesionless slopes. Journal of Geotechnical and Geoenvironmental Engineering, 139(11):1986-1993. https://doi.org/10.1061/(ASCE)GT.1943-5606.0000909

Kumar, J. \& Ghosh, P. (2007). Upper bound limit analysis for finding interference effect of two nearby strip footings on sand. Geotechnical and Geological Engineering, 25(5):499-507. https://doi.org/10.1007/s10706-007-9124-9

Kumar, J. \& Kouzer, K. (2008). Bearing capacity of two interfering footings. International Journal for Numerical and Analytical Methods in Geomechanics, 32(3):251-264. https://doi.org/10.1002/nag.625

Kumar, J. \& Kumar, N. (2003). Seismic bearing capacity of rough footings on slopes using limit equilibrium. Geotechnique, 53(3):363-369. https://doi.org/10.1680/geot.2003.53.3.363

Kumar, J. \& Mohan Rao, V. (2002). Seismic bearing capacity factors for spread foundations. Geotechnique, 52(2):79-88. https://doi.org/10.1680/geot.2002.52.2.79

Kumar, J. \& Mohan Rao, V. (2003). Seismic bearing capacity of foundations on slopes. Geotechnique, 53(3):347-361. https://doi.org/10.1680/geot.2003.53.3.347

Lee, J. \& Eun, J. (2009). Estimation of bearing capacity for multiple footings in sand. Computers and Geotechnics, 
36(6):1000-1008.

https://doi.org/10.1016/j.compgeo.2009.03.009

Luo, W.; Zhao, M.; Xiao, Y.; Zhang, R. \& Peng, W. (2019). Seismic bearing capacity of strip footings on cohesive soil slopes by using adaptive finite element limit analysis. Advances in Civil Engineering, 2019(1):1-16. https://doi.org/10.1155/2019/4548202

Mabrouki, A.; Benmeddour, D.; Frank, R. \& Mellas, M. (2010). Numerical study of the bearing capacity for two interfering strip footings on sands. Computers and Geotechnics, 37(4):431-439. https://doi.org/10.1016/j.compgeo.2009.12.007

Meyerhof, G.G. (1963). Some recent research on the bearing capacity of foundations. Canadian Geotechnical Journal, 1(1):16-26. https://doi.org/10.1139/t63-003

Pain, A.; Choudhury, D. \& Bhattacharyya, S. (2016). The Seismic Bearing Capacity Factor for Surface Strip Footings. Geo-Chicago, Chicago, Illinois, pp. 197-206. https://doi.org/10.1061/9780784480120.021

Pane, V.; Vecchietti, A. \& Cecconi, M. (2016). A numerical study on the seismic bearing capacity of shallow foundations. Bulletin of Earthquake Engineering, 14(11):2931-2958. https://doi.org/10.1007/s10518-016-9937-0

Paolucci, R. \& Pecker, A. (1997). Seismic bearing capacity of shallow strip foundations on dry soils. Soils and Foundations, 37(3):95-105. https://doi.org/10.3208/sandf.37.3_95

Prandtl, L. (1920). Über die härte plastischer körper. Nachrichten von der Gesellschaft der Wissenschaften zu Göttingen, Mathematisch-Physikalische Klasse, 1920(1):74-85.

Richards, J.; Elms, D. \& Budhu, M. (1993). Seismic bearing capacity and settlements of foundations. Journal of Geotechnical Engineering, 119(4):662-674. https://doi.org/10.1061/(ASCE)0733-9410(1993)119:4 (662)

Saha, A. \& Ghosh, S. (2015). Pseudo-dynamic analysis for bearing capacity of foundation resting on $c-\Phi$ soil. International Journal of Geotechnical Engineering,
9(4):379-387.

https://doi.org/10.1179/1939787914Y.0000000081

Sarma, S. \& Chen, Y. (1995). Seismic bearing capacity of shallow strip footings near sloping ground. Proc. 5th Conference on European Seismic Design Practice, SECED, Balkema, Rotterdam, pp.505-512.

Sarma, S. \& Iossifelis, I. (1990). Seismic bearing capacity factors of shallow strip footings. Geotechnique, 40(2):265-273.

https://doi.org/10.1680/geot.1990.40.2.265

Schmertmann, J.H.; Hartman, J.P. \& Brown, P.R. (1978). Improved strain influence factor diagrams. Journal of Geotechnical and Geoenvironmental Engineering, 104(8):1131-1135.

Shafiee, A.H. \& Jahanandish, M. (2010). Seismic bearing capacity factors for strip footings. Proc 5th National Congress on Civil Engineering, Mashhad, Iran, pp.1-8.

Shokoohi, M.; Veiskarami, M. \& Hataf, N. (2019). A numerical and analytical study on the bearing capacity of two neighboring shallow strip foundations on sand. Iranian Journal of Science and Technology, Transactions of Civil Engineering, 43(1):591-602. https://doi.org/10.1007/s40996-018-0189-x

Soubra, A.H. (1999). Upper-bound solutions for bearing capacity of foundations. Journal of Geotechnical and Geoenvironmental Engineering, 125(1):59-68. https://doi.org/10.1061/(ASCE)1090-0241(1999)125:1 (59)

Stuart, J. (1962). Interference between foundations, with special reference to surface footings in sand. Geotechnique, 12(1):15-22. https://doi.org/10.1680/geot.1962.12.1.15

Terzaghi, K. (1943). Theoretical Soil Mechanics. John Willey \& Sons, New York.

Vesic, A.S. (1973). Analysis of ultimate loads of shallow foundations. Journal of Soil Mechanics \& Foundations Div ASCE, 99(1):45-73.

Zeng, X. \& Steedma, R. (1998). Bearing capacity failure of shallow foundations in earthquakes. Geotechnique, 48(2):235-256.

https://doi.org/10.1680/geot.1998.48.2.235 